\title{
Cobalt Nanoparticles Promoted Highly Efficient One Pot Four-Component Synthesis of 1,4-Dihydropyridines under Solvent-Free Conditions
}

\author{
Javad SAFARI ${ }^{1, *}$, Sayed Hossein BANITABA ${ }^{1}$, Shiva DEHGHAN KHALILI ${ }^{1,2}$ \\ ${ }^{1}$ Laboratory of Organic Chemistry Research, Department of Organic Chemistry, College of Chemistry, \\ University of Kashan, Kashan, 87317-51167, Iran \\ ${ }^{2}$ Islamic Azad University Najafabad Branch, Najafabad, 85141-43131, Iran
}

\begin{abstract}
A straightforward and general method has been developed for the synthesis of $\mathrm{C}_{5}$-unsubstitiuted 1,4-dihydropyridines by a reaction using dimedone, acetophenone, aromatic aldehydes, and ammonium acetate in the presence of a catalytic amount of Co nanoparticles as a heterogeneous and eco-friendly catalyst with high catalytic activity at room temperature under solvent-free conditions. This catalyst is easily separated by magnetic devices and can be reused without any apparent loss of activity for the reaction. In addition, it is very interesting that when using Co nanoparticles as a catalyst, spatially-hindered aldehydes such as 2-methoxy-, 2-fluoro-, and 2-chloro-aldehydes are suitable for this reaction.
\end{abstract}

Key words: cobalt nanoparticle; 1,4-dihydropyridine; four-component condensation; heterogeneou catalyst; magnetically separable catalyst CLC number: O643 Document code: A

Received 14 June 2011. Accepted 12 October 2011

*Corresponding author.Tel: +98-361-591-2320; Fax:+98-361-591-2397; E-mail: Safarijav@yahoo.com, Safari@kashanu.ac.ir This work was supported by the University Grants Commission, University of Kashan.

English edition available online at Elsevier ScienceDirect (http://www.sciencedirect.com/science/journal/18722067)

The efficiency of heterogeneous catalysis in organic synthesis can be improved by nanosized catalysts because of their extremely small size and their large surface to volume ratios [1]. Homogeneous systems have the advantage of high catalytic activity and selectivity, but the catalysts are difficult to separate from the products. To improve catalyst separation much effort has been devoted to organic reactions in heterogeneous mode [2,3]. Recently, it has been shown that Co nanoparticles (Co NPs), as catalysts, offer great opportunities for a wide range of applications in organic synthesis and in chemical manufacturing processes [4-9]. Green chemistry emphasizes the development of environmentally benign chemical processes and technologies [10]. Besides typical multi-step syntheses, an increasing number of organic chemical compounds are being produced by multicomponent reactions (MCRs). MCRs often comply with the principles of green chemistry in terms of the economy of steps as well as the many stringent criteria of ideal organic synthesis. MCRs offer great possibilities for molecular diversity per step with a minimum synthesis time, labor, cost, and waste production. As a one-pot reaction, MCRs generally afford good yields and are fundamentally different from two-component and stepwise reactions in several ways [11] and they permit rapid access to combina- torial libraries of complex organic molecules for an efficient lead structure identification and for optimization in drug discovery. 1,4-Dihydropyridines (1,4-DHPs) are an important class of compounds in the field of drugs and pharmaceuticals [12-16]. The DHP moiety is common to numerous bioactive compounds and these include various antihypertensives such as nifedipine, nicardipine and amlodipine, vasodilator, antimutagenic, antitumor, and antidiabetic agents [17-20]. These examples clearly demonstrate the remarkable potential of 1,4-DHPs derivatives as a source of valuable drugs. Despite the many methods available for the synthesis of dihydropyridine derivatives [21-35], their widespread use has accentuated the need to develop new synthetic routes for $N$-heterocycles containing the dihydropyridine moiety. Recent protocols have employed three-component condensations of dimedone, chalcone derivatives, and ammonium acetate [36,37]. Synthetic methods should be designed to use substances that have little or no toxicity to human health and the environment. Therefore, the possibility of performing multicomponent reactions under solvent-free conditions with heterogeneous catalysts like Co NPs as a magnetically separable catalyst can enhance their efficiency from an economic as well as a green point of view. Thus, the remarkable catalytic activity and 


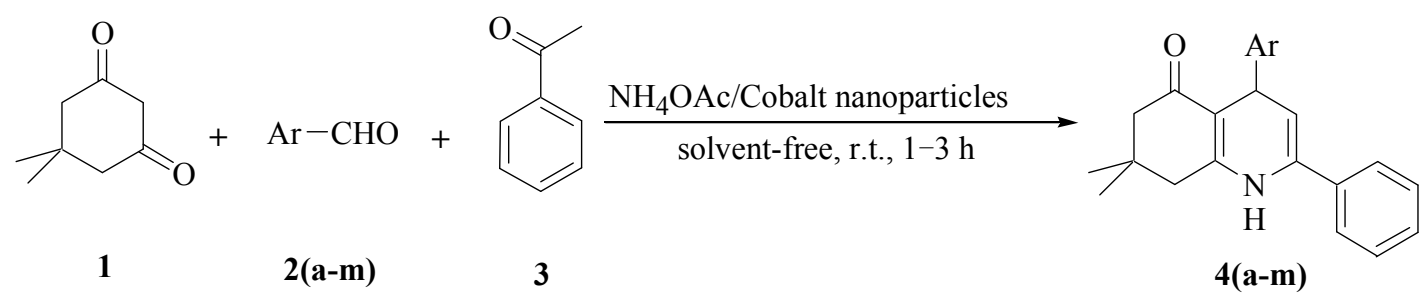

Scheme 1. Co NPs efficiently catalyzed synthesis of 1,4-DHPs.

easy synthesis, operational simplicity, eco-friendliness, and recoverability of Co NPs encouraged us to use it as a catalyst for the synthesis of 1,4-DHPs [38]. To the best of our knowledge there are no examples of the use of Co NPs as catalysts for the four-component synthesis of $\mathrm{C}_{5}$-unsubstitiuted 1,4-DHPs. In a continuation of our effort to develop new and green chemistry methods as well as our interest in applications of heterogeneous-catalyzed organic reactions [39] we explored the possibility of synthesizing pure metallic Co NPs and $\mathrm{C}_{5}$-unsubstitiuted 1,4-DHPs by a one-pot and four-component reaction under solvent-free conditions using Co NPs as a recyclable and magnetically separable catalyst at room temperature, as shown in Scheme 1.

\section{Experimental}

\subsection{General}

All reagents were purchased from Merck and Aldrich and used without further purification. Melting points were determined in open capillaries using an Electrothermal $\mathrm{Mk} 3$ apparatus and are uncorrected. Infrared (IR) spectra were recorded using a Perkin-Elmer FT-IR 550 spectrometer. ${ }^{1} \mathrm{H}$ NMR and ${ }^{13} \mathrm{C}$ NMR spectra were recorded with a Bruker DRX-400 spectrometer at 400 and $100 \mathrm{MHz}$, respectively. NMR spectra were obtained in $\mathrm{CDCl}_{3}$ solutions. Elemental analyses $(\mathrm{C}, \mathrm{H}$, and $\mathrm{N})$ were obtained using a Carlo ERBA Model EA 1108 analyzer and carried out on a Perkin-Elmer 240c analyzer. X-ray diffraction (XRD) patterns were recorded on an X-ray diffractometer (PAN analytical X'pert-pro) using a $\mathrm{Cu} K_{\alpha}$ monochromatized radiation source and a Ni filter in a $2 \theta$ range of $30^{\circ}-90^{\circ}$. BET surface area analyses were performed at $-196{ }^{\circ} \mathrm{C}$ using an automated gas adsorption analyzer (Tristar 3000, Micromeritics). The composition and microstructure of the specimens were analyzed using a scanning electron microscope (SEM, JSM-5600LV) equipped with an energy-dispersion analytical X-ray spectroscope (EDS).

\subsection{Catalyst preparation}

A dark blue solution was formed after dissolving the co- balt salt $\left(\mathrm{CoCl}_{2} \cdot 6 \mathrm{H}_{2} \mathrm{O}\right.$ or $\left.\mathrm{CoSO}_{4} \cdot 7 \mathrm{H}_{2} \mathrm{O}\right)$ in ethanol and then a mixture of hydrazine hydrate $\left(\mathrm{N}_{2} \mathrm{H}_{4} \cdot \mathrm{H}_{2} \mathrm{O}\right)$ and sodium hydroxide $(\mathrm{NaOH})$ was added to the dark blue solution at $200{ }^{\circ} \mathrm{C}$. After about $30 \mathrm{~min}$, gray solid particles appeared and reacted quickly. The suspended gray particles can be precipitated by placing a magnet under the container. After reaction completion the gray particles were washed with distilled water, ethanol, and absolute ethanol to remove hydrazine, sodium, and chlorine ions. The sample was then kept in absolute ethanol [40].

\subsection{Synthesis of $\mathrm{C}_{5}$-unsubstitiuted 1,4-DHPs}

Dimedone $(1 \mathrm{mmol})$ and an aromatic aldehyde $(1 \mathrm{mmol})$ were added to a mixture of acetophenone $(1 \mathrm{mmol})$, ammonium acetate $(1 \mathrm{mmol})$, and Co NPs $(10 \mathrm{~mol} \%)$. The mixture was then stirred at room temperature. The reaction was completed within 1-2 $\mathrm{h}$, as confirmed by TLC. The mixture was then extracted with ethyl acetate and the organic layer was dried over sodium sulphate and concentrated in a vacuum to afford the crude products. The Co NPs were recovered using a magnet and reused four times in the same reaction (Table 5).

4-(3,4-dimethoxyphenyl)-7,7-dimethyl-2-phenyl-4,6,7, 8-tetrahydro-5(1H)-quinolinone $(\mathbf{4 g})$ : $\mathrm{mp} 201-203{ }^{\circ} \mathrm{C}$; IR $\left(\mathrm{KBr}, \mathrm{cm}^{-1}\right) 3341,1674,1729 ;{ }^{1} \mathrm{H}$ NMR $\left(400 \mathrm{MHz}, \mathrm{CDCl}_{3}\right)$ : $\delta 1.15(\mathrm{~s}, 3 \mathrm{H}), 1.16(\mathrm{~s}, 3 \mathrm{H}), 2.22-2.50(\mathrm{~m}, 4 \mathrm{H}), 3.72(\mathrm{~s}, 3 \mathrm{H})$, $3.75(\mathrm{~s}, 3 \mathrm{H}), 4.66(\mathrm{~d}, J=5.1 \mathrm{~Hz}, 1 \mathrm{H}), 5.22(\mathrm{~d}, J=5.1 \mathrm{~Hz}$, $1 \mathrm{H}), 5.81(\mathrm{~s}, 1 \mathrm{H}, \mathrm{NH}), 6.82(\mathrm{~s}, 1 \mathrm{H}), 7.0-7.30(\mathrm{~m}, 5 \mathrm{H}), 7.34$ $(\mathrm{d}, J=8.1 \mathrm{~Hz}, 1 \mathrm{H}), 7.52(\mathrm{~d}, J=8.1 \mathrm{~Hz}, 1 \mathrm{H}) ;{ }^{13} \mathrm{C} \mathrm{NMR}(100$ $\left.\mathrm{MHz}, \mathrm{CDCl}_{3}\right): \delta 26.9,29.3,32.5,36.5,42.5,50.3,57.5$, 57,8, 107.4, 107.9, 111.5, 121.2, 125.8, 126.7, 128.4, 128.9, 129.1, 129.8, 135.1, 135.7, 148.4, 151.4, 196.8; Anal. Calcd. for $\mathrm{C}_{25} \mathrm{H}_{27} \mathrm{NO}_{3}$ : C, 77.09; H, 6.99; N, 3.60. Found: C, 76.98; H, 6.95; N, 3.58 .

4-(3-Bromoyphenyl)-7,7-dimethyl-2-phenyl-4,6,7,8-tetrahydro-5(1H)-quinolinone (4h): mp 224-227 ${ }^{\circ} \mathrm{C}$; IR (KBr, $\mathrm{cm}^{-1}$ ) 3340, 1668, 1733; ${ }^{1} \mathrm{H}$ NMR (400 MHz, $\left.\mathrm{CDCl}_{3}\right): \delta$ $1.14(\mathrm{~s}, 3 \mathrm{H}), 1.15$ (s, 3H), 2.20-2.40 (m, 4H), 4.64 (d, $J=$ $4.9 \mathrm{~Hz}, 1 \mathrm{H}), 5.27(\mathrm{~d}, J=4.9 \mathrm{~Hz}, 1 \mathrm{H}), 5.75(\mathrm{~s}, 1 \mathrm{H}, \mathrm{NH})$, $7.0-7.30(\mathrm{~m}, 5 \mathrm{H}), 7.32$ (s, 1H), $7.38(\mathrm{~d}, J=7.5 \mathrm{~Hz}, 1 \mathrm{H})$, $7.54(\mathrm{~d}, J=7.3 \mathrm{~Hz}, 1 \mathrm{H}), 7.69$ (dd, $J=7.5 \mathrm{~Hz}, J=7.3 \mathrm{~Hz}$, $1 \mathrm{H}) ;{ }^{13} \mathrm{C}$ NMR (100 MHz, $\left.\mathrm{CDCl}_{3}\right): \delta 26.8,29.8,33.1,36.1$, 
$41.2,51.8,106.9,108.5,110.4,112.8,125.1,127.3,128.4$, 129.4, 129.5, 130.4, 135.7, 136.4, 149.1, 156.2, 196.3; Anal. Calcd. for $\mathrm{C}_{23} \mathrm{H}_{22} \mathrm{BrNO}$ : C, 67.65; H, 5.43; N, 3.43. Found: C, 67.49; H, 5.40; N, 3.39.

4-(3-chloroyphenyl)-7,7-dimethyl-2-phenyl-4,6,7,8-tetrahydro-5(1H)-quinolinone (4i): $\mathrm{mp} 214-217^{\circ} \mathrm{C}$; IR $(\mathrm{KBr}$, $\mathrm{cm}^{-1}$ ) 3341, 1664, 1732; ${ }^{1} \mathrm{H}$ NMR (400 MHz, $\left.\mathrm{CDCl}_{3}\right): \delta$ $1.16(\mathrm{~s}, 3 \mathrm{H}), 1.17(\mathrm{~s}, 3 \mathrm{H}), 2.22-2.45(\mathrm{~m}, 4 \mathrm{H}), 4.55$ (d, $J=$ $4.8 \mathrm{~Hz}, 1 \mathrm{H}), 5.23(\mathrm{~d}, J=4.8 \mathrm{~Hz}, 1 \mathrm{H}), 5.72(\mathrm{~s}, 1 \mathrm{H}, \mathrm{NH})$, $7.0-7.40(\mathrm{~m}, 5 \mathrm{H}), 7.42(\mathrm{~s}, 1 \mathrm{H}), 7.47(\mathrm{~d}, J=7.2 \mathrm{~Hz}, 1 \mathrm{H})$, $7.52(\mathrm{~d}, J=7.8 \mathrm{~Hz}, 1 \mathrm{H}), 7.74(\mathrm{dd}, J=7.8 \mathrm{~Hz}, J=7.2 \mathrm{~Hz}$, $1 \mathrm{H}) ;{ }^{13} \mathrm{C} \mathrm{NMR}\left(100 \mathrm{MHz}, \mathrm{CDCl}_{3}\right): \delta 26.1,29.4,33.7,35.4$, 42.5, 52.1, 107.5, 108.7, 111.1, 112.2, 125.5, 126.7, 128.8, 129.1, 130.5, 131.1, 134.1, 136.8, 150.8, 157.1, 197.4; Anal. Calcd. for $\mathrm{C}_{23} \mathrm{H}_{22} \mathrm{ClNO}$ : C, 75.92; H, 6.09; N, 3.85. Found: C, 75.90; H, 5.35; N, 3.35.

4-(4-bromophenyl)-7,7-dimethyl-2-phenyl-4,6,7,8-tetrahydro-5(1H)-quinolinone $(4 \mathbf{j})$ : mp $217-220^{\circ} \mathrm{C}$; IR $(\mathrm{KBr}$, $\mathrm{cm}^{-1}$ ) 3344, 1679, 1731; ${ }^{1} \mathrm{H}$ NMR (400 MHz, $\left.\mathrm{CDCl}_{3}\right): \delta$ $1.11(\mathrm{~s}, 3 \mathrm{H}), 1.13(\mathrm{~s}, 3 \mathrm{H}), 2.20-2.50(\mathrm{~m}, 4 \mathrm{H}), 4.74(\mathrm{~d}, J=$ $4.7 \mathrm{~Hz}, 1 \mathrm{H}), 5.34(\mathrm{~d}, J=4.7 \mathrm{~Hz}, 1 \mathrm{H}), 5.79$ (s, 1H, NH), $7.0-7.25(\mathrm{~m}, 5 \mathrm{H}), 7.36(\mathrm{~d}, J=7.9 \mathrm{~Hz}, 2 \mathrm{H}), 7.45$ (d, $J=7.9$ $\mathrm{Hz}, 2 \mathrm{H}) ;{ }^{13} \mathrm{C}$ NMR $\left(100 \mathrm{MHz}, \mathrm{CDCl}_{3}\right): \delta 27.4,29.4,32.7$, $37.9,41.9,50.7,107.1,108.3,125.2,126.1,127.9,128.3$, 128.7, 128.8, 134.2, 135.8, 147.7, 151.0, 195.5; Anal. Calcd. for $\mathrm{C}_{23} \mathrm{H}_{22} \mathrm{BrNO}$ : C, 67.65; H, 5.43; N, 3.43. Found: C, 67.49; H, 5.40; N, 3.39.

4-(2-fluorophenyl)-7,7-dimethyl-2-phenyl-4,6,7,8-tetrahydro-5(1H)-quinolinone (4k): mp $198-200{ }^{\circ} \mathrm{C}$; IR $(\mathrm{KBr}$, $\mathrm{cm}^{-1}$ ) 3337, 1672, 1750; ${ }^{1} \mathrm{H}$ NMR (400 MHz, $\left.\mathrm{CDCl}_{3}\right): \delta$ $1.08(\mathrm{~s}, 3 \mathrm{H}), 1.12$ (s, 3H), 2.25-2.57 (m, 4H), 4.68 (d, $J=$ $4.8 \mathrm{~Hz}, 1 \mathrm{H}), 5.29(\mathrm{~d}, J=4.8 \mathrm{~Hz}, 1 \mathrm{H}), 5.67$ (s, 1H, NH), $6.95(\mathrm{dd}, J=9.2 \mathrm{~Hz}, J=8.4 \mathrm{~Hz}, 1 \mathrm{H}), 7.21(\mathrm{dd}, J=7.6 \mathrm{~Hz}, J$ $=7.2 \mathrm{~Hz}, 1 \mathrm{H}), 7.32(\mathrm{~d}, J=7.6 \mathrm{~Hz}, 1 \mathrm{H}), 7.42(\mathrm{dd}, J=8.4$ $\mathrm{Hz}, J=7.2 \mathrm{~Hz}, 1 \mathrm{H}), 7.6-7.90(\mathrm{~m}, 5 \mathrm{H}) ;{ }^{13} \mathrm{C} \mathrm{NMR}(100$ $\left.\mathrm{MHz}, \mathrm{CDCl}_{3}\right): \delta 27.4,29.4,32.7,37.9,41.9,50.7$ (d, $J=9.2$ $\mathrm{Hz}), 107.1,108.3,116.7$ (d, $J=21.4 \mathrm{~Hz}), 125.2,126.1$, 127.9, 127.9 (d, $J=21.7 \mathrm{~Hz}), 128.3,129.7$ (d, $J=7.9 \mathrm{~Hz})$, 128.8, 134.2, 135.8, 147.7, $161.0(\mathrm{~d}, J=249 \mathrm{~Hz}), 195.5$; Anal. Calcd. for $\mathrm{C}_{23} \mathrm{H}_{22} \mathrm{FNO}$ : C, 69.51; H, 6.38; N, 4.03 . Found: C, 69.46; H, 5.38; N, 3.35.

4-(4-fluorophenyl)-7,7-dimethyl-2-phenyl-4,6,7,8-tetrahydro-5(1H)-quinolinone (4l): $\mathrm{mp} 210-213{ }^{\circ} \mathrm{C}$; IR $(\mathrm{KBr}$, $\mathrm{cm}^{-1}$ ) 3339, 1676, 1735; ${ }^{1} \mathrm{H}$ NMR (400 MHz, $\left.\mathrm{CDCl}_{3}\right): \delta$ 1.15 (s, 3H), 1.17 (s, 3H), 2.29-2.40 (m, 4H), 4.56 (d, $J=$ $5.1 \mathrm{~Hz}, 1 \mathrm{H}), 5.02(\mathrm{~d}, J=5.1 \mathrm{~Hz}, 1 \mathrm{H}), 6.13(\mathrm{~s}, 1 \mathrm{H}, \mathrm{NH})$, $6.80(\mathrm{dd}, J=8.9 \mathrm{~Hz}, J=7.4 \mathrm{~Hz}, 2 \mathrm{H}), 7.31(\mathrm{dd}, J=8.9 \mathrm{~Hz}, J$ $=4.2 \mathrm{H}), 7.6-8.55(\mathrm{~m}, 5 \mathrm{H}) ;{ }^{13} \mathrm{C} \mathrm{NMR}\left(100 \mathrm{MHz}, \mathrm{CDCl}_{3}\right)$ : $\delta 26.8,29.9,32.2,36.2,42.4,49.9,107.4,108.8,123.2$ (d, $J$ $=22 \mathrm{~Hz}), 126.1,127.9,128.3(\mathrm{~d}, J=8 \mathrm{~Hz}), 129.7,138.8$, 139.2, 140.8, 150.6, 163.5 (d, $J=244 \mathrm{~Hz}), 194.5$; Anal. Calcd. for $\mathrm{C}_{23} \mathrm{H}_{22} \mathrm{FNO}$ : C, 69.51; H, 6.38; N, 4.03. Found:
C, 69.46; H, 5.38; N, 3.35 .

4-(2-methoxyphenyl)-7,7-dimethyl-2-phenyl-4,6,7,8-tetrahydro-5(1H)-quinolinone (4m): mp $196-199{ }^{\circ} \mathrm{C}$; IR (KBr, $\mathrm{cm}^{-1}$ ) 3343, 1666, 1745; ${ }^{1} \mathrm{H}$ NMR (400 MHz, $\left.\mathrm{CDCl}_{3}\right): \delta$ $1.13(\mathrm{~s}, 3 \mathrm{H}), 1.19$ (s, 3H), 2.21-2.40 (m, 4H), 4.67 (d, $J=$ $4.4 \mathrm{~Hz}, 1 \mathrm{H}), 5.62(\mathrm{~d}, J=4.4 \mathrm{~Hz}, 1 \mathrm{H}), 5.58(\mathrm{~s}, 1 \mathrm{H}, \mathrm{NH})$, $7.06(\mathrm{~d}, J=8.1 \mathrm{~Hz}, 1 \mathrm{H}), 7.11(\mathrm{dd}, J=7.9 \mathrm{~Hz}, J=7.3 \mathrm{~Hz}$, 1H), 7.14 (d, $J=7.3 \mathrm{~Hz}, 1 \mathrm{H}), 7.27$ (dd, $J=8.1 \mathrm{~Hz}, J=7.9$ $\mathrm{Hz}, 1 \mathrm{H}), 7.36-7.50(\mathrm{~m}, 5 \mathrm{H}) ;{ }^{13} \mathrm{C}$ NMR $\left(100 \mathrm{MHz}, \mathrm{CDCl}_{3}\right)$ : $\delta 27.4,29.4,32.7,37.9,41.9,50.7,57.4,108.3,110.6$, $122.7,125.3,125.9,126.4,126.8,127.3,128.2,131.6$, 132.7, 138.3, 140.2, 197.9; Anal. Calcd. for $\mathrm{C}_{24} \mathrm{H}_{25} \mathrm{NO}_{2}$ : C, 80.19; H, 7.01, N, 3.90. Found: C, 80.07; H, 6.98; N, 3.86.

\section{Results and discussion}

We had the opportunity to further explore the catalytic activity of Co NPs for the synthesis of 1,4-DHPs. The crystallite size of the Co NPs was determined by XRD and the results are presented in Fig. 1(a). The XRD peaks were FCC (111), (200), and (220) for the sample synthesized at $200{ }^{\circ} \mathrm{C}$ in an ethanol hydrazine alkaline system and were assigned using JCPDS 15-806 for the cubic lattice. An examination of the sample by SEM (Fig. 1(b)) reveals that the diameters of the nanoparticles are less than $90 \mathrm{~nm}$, which agrees with the size calculated from the XRD pattern using the Scherrer equation.

The lattice parameter of the prepared Co NPs was 0.204
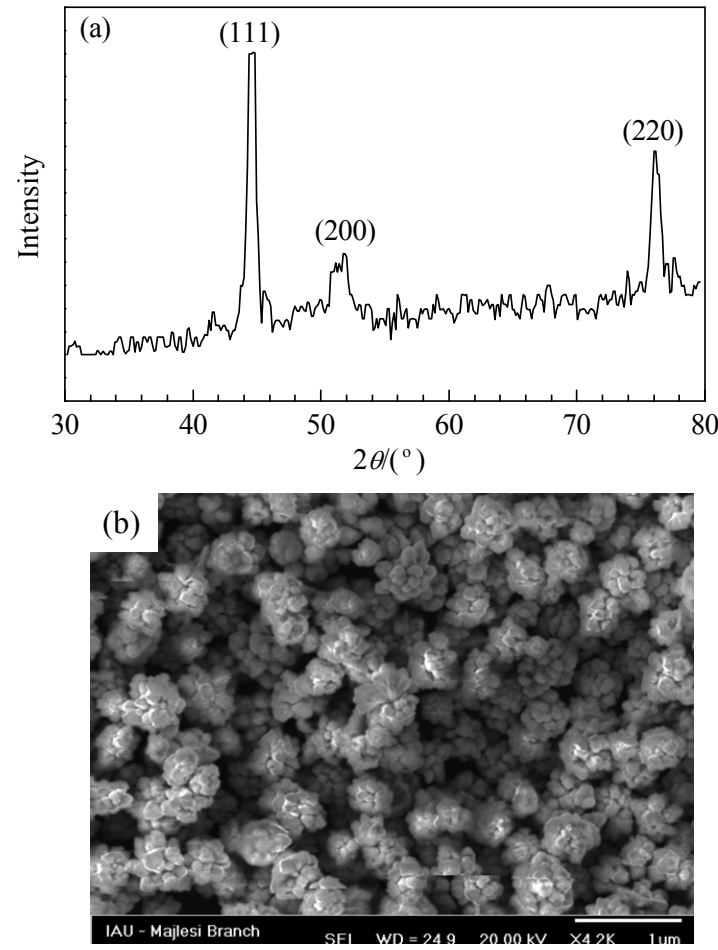

Fig. 1. XRD pattern (a) and SEM image (b) of the prepared Co NPs in ethanol hydrazine alkaline system. 
$\mathrm{nm}$, which is in good agreement with JCPDS 15-806. The crystallite sizes were $83.2,78.8$, and $77.4 \mathrm{~nm}$, respectively, calculated on the (111), (200), and (220) diffraction maxima from the half-width of the diffraction peak using Scherrer formula.

In addition the surface area was found to be approximately $95 \mathrm{~cm}^{3} / \mathrm{g}$. The pore volume and pore size were also calculated from the $\mathrm{N}_{2}$ adsorption result. The pore size was found to be approximately $46.17 \mathrm{~nm}$ and the pore volume approximately $1.55 \mathrm{~cm}^{3} / \mathrm{g}$. The theoretical particle size was also calculated from the surface area, assuming spherical particles, from the equation $D_{\mathrm{BET}}=6000 /(\rho \times S)$, where $D_{\mathrm{BET}}$ is the equivalent particle diameter in $\mathrm{nm}, \rho$ is the density of the material in $\mathrm{g} / \mathrm{cm}^{3}$ and $S$ is the specific surface area in $\mathrm{m}^{2} / \mathrm{g}$. The particle size calculated from the equation was $87.93 \mathrm{~nm}$, which confirmed the nanostructure of the Co NPs sample. The difference between the particle morphology and the size distribution that was obtained at different temperatures and at different $\mathrm{Co}^{2+}$ concentrations can be explained by the reaction rate of nucleation [40].

Subsequent efforts focused on optimizing the concentration of the catalyst Co NPs and we investigated the model reaction between dimedone, benzaldehyde, acetophenone, and ammonium acetate at different concentrations of Co NPs such as $2 \mathrm{~mol} \%$, $4 \mathrm{~mol} \%, 6 \mathrm{~mol} \%, 8 \mathrm{~mol} \%, 10 \mathrm{~mol} \%$, and $12 \mathrm{~mol} \%$. Products were obtained in $35 \%, 45 \%, 60 \%$, $75 \%, 98 \%$, and $90 \%$ yields, respectively. This indicates that $10 \mathrm{~mol} \%$ of Co NPs produced the best results with respect to the product yield (Table 1).

Table 1 Optimizing the reaction conditions

\begin{tabular}{cccc}
\hline Entry & Co NPs $(\mathrm{mol} \%)$ & Time $(\mathrm{h})$ & Isolated yield $(\%)$ \\
\hline 1 & 0 & 6.0 & 30 \\
2 & 2 & 3.0 & 35 \\
3 & 4 & 3.0 & 45 \\
4 & 6 & 3.0 & 60 \\
5 & 8 & 3.0 & 75 \\
6 & 10 & 1.0 & 98 \\
7 & $10^{\mathrm{a}}$ & 6.0 & 50 \\
8 & 12 & 3.0 & 90 \\
\hline
\end{tabular}

Reaction conditions: dimedone:benzaldehyde:acetophenone:ammonium acetate $=1: 1: 1: 1 .{ }^{a}$ Using commercial cobalt powder.

We then continued to optimize the model process mentioned above by determining the efficiency of several classic solvents that were chosen as a medium for comparison. In each case, the substrates were mixed with $10 \mathrm{~mol} \% \mathrm{Co}$ NPs and agitated with 3-5 ml of solvent. Among the tested solvents such as methanol, ethanol, acetonitrile, dichloromethane, water, and a solvent-free system, the formation of product 4a was found to be more facile and proceeded to give the highest yield only under solvent-free reaction conditions (Table 2).
Table 2 Solvent screening for the reaction between dimedone, benzaldehyde, acetophenone, and ammonium acetate

\begin{tabular}{cccc}
\hline Entry & Solvent & Time $(\mathrm{h})$ & Isolated yield (\%) \\
\hline 1 & EtOH & 6.0 & 60 \\
2 & $\mathrm{MeOH}$ & 6.0 & 50 \\
3 & acetonitrile & 6.0 & 30 \\
4 & dichloromethane & 24.0 & trace \\
5 & water & 6.0 & 80 \\
6 & none & 1.0 & 98 \\
\hline
\end{tabular}

Reaction conditions: Co NPs $(10 \% \mathrm{~mol})$, dimedone:benzaldehyde: acetophenone:ammonium acetate $=1: 1: 1: 1$.

A possible explanation for the higher yield under solvent-free conditions is that the eutectic mixture has a uniform distribution of reactants and the reacting species are in closer proximity for the reaction compared with that in a solvent. The environment of the reaction system in the absence of a solvent is different from that in solution resulting in a higher concentration of local reaction sites and an improved global efficiency. To further expand the scope of this method the replacement of Co NPs by commercial cobalt powder was examined. We carried out a reaction between dimedone (1), benzaldehyde (2a), acetophenone (3), and ammonium acetate using the commercial cobalt powder (10 mol\%) under solvent-free conditions at room temperature. When the reaction was carried out using the commercial cobalt powder, $50 \%$ of product $4 \mathrm{a}$ was obtained in $6 \mathrm{~h}$. The catalytic activity of the Co NPs was evident when only $30 \%$ and $50 \%$ product was obtained in the absence of the catalyst and when using the commercial cobalt powder, respectively (Table 1, entries 1 and 7). The high efficiency of the metal nanoparticles is caused by their high surface area and also by the high concentration of low-coordinated sites and structural defects on their surface. As the particle size is scaled down to a few nanometers, the constituent atoms have highly defective coordination environments. These properties of the Co NPs gave spatially-hindered aldehydes such as 2-methoxy-, 2-fluoro-, and 2-chloro-aldehydes, which function well in this reaction (Table 3). The Co NPs also act as a mild Lewis acid and catalyze the four-component, one-pot synthesis of $\mathrm{C}_{5}$-unsubstitiuted 1,4-DHPs.

An investigation into the reaction scope revealed that various aromatic aldehydes (bearing electron-withdrawing and electron-donating groups) can be used in this protocol (Table 3). The nature of the substituent on the aromatic ring had no obvious effect on this conversion because high yields were obtained over relatively short reaction times. The structures of the isolated products $4 \mathbf{a}-\mathbf{4 m}$ were determined by IR, ${ }^{1} \mathrm{H}$ NMR and ${ }^{13} \mathrm{C}$ NMR spectroscopy, and elemental analysis.

After successfully synthesizing a series of polyhydroquinolines in excellent yields, we used $\beta$-ketoesters to show the validity of this methodology. We thus carried out a 
Table 3 Co NPs catalyzed unsymmetrical one-pot four-component synthesis of 1,4-DHPs

\begin{tabular}{|c|c|c|c|c|c|}
\hline \multirow{2}{*}{ Product } & \multirow{2}{*}{$\mathrm{Ar}$} & \multirow{2}{*}{ Time (h) } & \multirow{2}{*}{ Isolated yield (\%) } & \multicolumn{2}{|c|}{ Melting point $\left({ }^{\circ} \mathrm{C}\right)$} \\
\hline & & & & Found & Reported \\
\hline $4 a$ & $\mathrm{C}_{6} \mathrm{H}_{5}$ & 1.0 & 98 & $203-205$ & $206-208$ [36] \\
\hline $4 b$ & 4- $\mathrm{ClC}_{6} \mathrm{H}_{4}$ & 1.5 & 90 & $222-224$ & $224-226[36]$ \\
\hline $4 c$ & $2,4-\mathrm{Cl}_{2} \mathrm{C}_{6} \mathrm{H}_{3}$ & $2.5,6.0^{\mathrm{a}}$ & $80,45^{\mathrm{a}}$ & 206-208 & 204-206 [36] \\
\hline $4 d$ & $4-\mathrm{NO}_{2} \mathrm{C}_{6} \mathrm{H}_{4}$ & 1.5 & 90 & $211-213$ & $212-214$ [37] \\
\hline $4 e$ & $4-\mathrm{CH}_{3} \mathrm{C}_{6} \mathrm{H}_{4}$ & 1.0 & 95 & 184-186 & $186-188$ [37] \\
\hline $4 f$ & $4-\mathrm{MeOC}_{6} \mathrm{H}_{4}$ & 1.0 & 92 & 190-192 & 192-194 [37] \\
\hline $4 \mathrm{~g}$ & $3,4-\mathrm{MeOC}_{6} \mathrm{H}_{3}$ & 1.5 & 88 & 201-203 & - \\
\hline $4 h$ & $3-\mathrm{BrC}_{6} \mathrm{H}_{4}$ & 1.5 & 94 & $224-227$ & - \\
\hline $4 i$ & $3-\mathrm{ClC}_{6} \mathrm{H}_{4}$ & 1.5 & 92 & $214-216$ & - \\
\hline $4 j$ & $4-\mathrm{BrC}_{6} \mathrm{H}_{4}$ & 1.5 & 92 & $217-220$ & - \\
\hline $4 k$ & $2-\mathrm{FC}_{6} \mathrm{H}_{4}$ & $2.0,6.0^{\mathrm{a}}$ & $75,40^{\mathrm{a}}$ & 198-201 & - \\
\hline 41 & $4-\mathrm{FC}_{6} \mathrm{H}_{4}$ & 1.0 & 95 & $210-213$ & - \\
\hline $4 \mathrm{~m}$ & $2-\mathrm{MeOC}_{6} \mathrm{H}_{4}$ & $3.0,6.0^{\mathrm{a}}$ & $65,30^{\mathrm{a}}$ & 196-199 & - \\
\hline
\end{tabular}

Reaction conditions: Co NPs $(10 \% \mathrm{~mol})$, dimedone:benzaldehyde:acetophenone:ammonium acetate $=1: 1: 1: 1$.

${ }^{\mathrm{a}}$ Using commercial cobalt powder.

four-component coupling reaction among dimedone, some aromatic aldehydes, alkyl acetoacetate, and ammonium acetate under the same reaction conditions.

The structural variation of the $\beta$-ketoesters did not obviously affect this conversion because the desired products were obtained in high yields and in relatively short reaction time (Table 4).

We examined the recovery and reuse of the catalyst. The catalyst was recovered using magnetic decantation and reused in four consecutive runs without any apparent loss of activity for the same reaction. The yield of the product in the second, third, and fourth runs was almost the same as that in the first run, as shown in Table 5.

Figure 2 shows EDAX patterns of the fresh and the 2nd recycle nanoparticles. Interestingly, the total composition of cobalt was found in the resultant sample. However, EDAX results show that the catalyst consists mainly of cobalt (98\%), and a small amount of oxygen is also present while no other elements were found using EDAX. The oxygen detected by EDAX might come from oxides such as $\mathrm{CoO}$ or

Table 5 Reuse of Co NPs in the synthesis of 1,4-DHPs

\begin{tabular}{cc}
\hline Run & Isolated yield (\%) \\
\hline Fresh & 98 \\
1 & 97 \\
2 & 97 \\
3 & 95 \\
4 & 94 \\
\hline
\end{tabular}

Reaction conditions: Co NPs (10\% mol), dimedone:benzaldehyde: acetophenone:ammonium acetate $=1: 1: 1: 1$.

Table 4 Co NPs catalyzed unsymmetrical one-pot four-component synthesis of 1,4-DHPs with different $\beta$-keto compounds<smiles>[R]OC(=O)C1=CNC2=C(C(=O)CC(C)(C)C2)C1[Y19]</smiles>
$5(\mathbf{a}-\mathbf{f})$

\begin{tabular}{|c|c|c|c|c|c|c|}
\hline \multirow{2}{*}{ Product } & \multirow{2}{*}{$\mathrm{R}$} & \multirow{2}{*}{$\mathrm{Ar}$} & \multirow{2}{*}{ Time (h) } & \multirow{2}{*}{ Isolated yield (\%) } & \multicolumn{2}{|c|}{ Melting point $\left({ }^{\circ} \mathrm{C}\right)$} \\
\hline & & & & & Found & Reported \\
\hline $5 \mathbf{a}$ & $\mathrm{Et}$ & $\mathrm{C}_{6} \mathrm{H}_{5}$ & 1.0 & 95 & $203-204$ & $202-203$ [28] \\
\hline $5 b$ & Et & $2-\mathrm{ClC}_{6} \mathrm{H}_{4}$ & 2.0 & 85 & $207-210$ & $208-210$ [28] \\
\hline $5 c$ & Et & $4-\mathrm{MeC}_{6} \mathrm{H}_{4}$ & 1.5 & 90 & $259-261$ & $260-261[28]$ \\
\hline $5 d$ & $\mathrm{Et}$ & 2-thienyl & 1.0 & 92 & $237-239$ & $238-240$ [28] \\
\hline $5 e$ & Et & $4-\mathrm{OMeC}_{6} \mathrm{H}_{4}$ & 1.5 & 93 & $258-260$ & $257-259$ [28] \\
\hline $5 f$ & Et & $3-\mathrm{BrC}_{6} \mathrm{H}_{4}$ & 1.0 & 90 & $234-237$ & $235-236[28]$ \\
\hline $5 g$ & $\mathrm{Me}$ & 2-thienyl & 1.5 & 90 & $216-218$ & $216-217$ [29] \\
\hline $5 h$ & $\mathrm{Me}$ & $4-\mathrm{ClC}_{6} \mathrm{H}_{4}$ & 1.0 & 95 & $221-222$ & $222-223$ [29] \\
\hline $5 i$ & $\mathrm{Me}$ & 4- $\mathrm{MeC}_{6} \mathrm{H}_{4}$ & 1.2 & 88 & $283-285$ & $>280[31]$ \\
\hline $5 \mathbf{j}$ & $\mathrm{Me}$ & $\mathrm{C}_{6} \mathrm{H}_{5}$ & 1.0 & 90 & $258-260$ & $260-261[35]$ \\
\hline $5 \mathrm{k}$ & $\mathrm{Me}$ & $3,4,5-\mathrm{OMeC}_{6} \mathrm{H}_{2}$ & 2.0 & 85 & $285-287$ & $>270[30]$ \\
\hline
\end{tabular}

Reaction conditions: Co NPs $(10 \% \mathrm{~mol})$, dimedone:benzaldehyde: $\beta$-ketoesters:ammonium acetate $=1: 1: 1: 1$. 


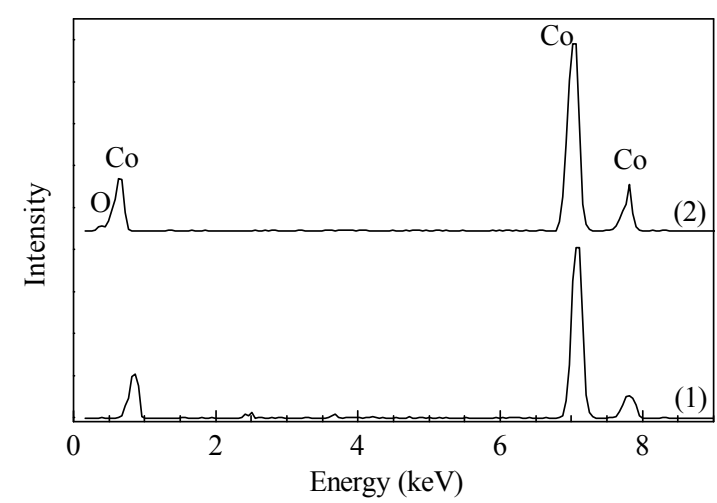

Fig. 2. EDAX patterns of fresh (1) and 2nd recycle (2) Co NPs.

$\mathrm{Co}_{3} \mathrm{O}_{4}$, as a result of the oxidation of cobalt during the reaction and after treatment.

\section{Conclusions}

A four-component reaction between dimedone, aromatic aldehydes, acetophenone, and ammonium acetate is shown to provide a simple synthetic route to $\mathrm{C}_{5}$-unsubstitiuted 1,4-dihydropyridines using Co nanoparticles. We demonstrate for the first time that $\mathrm{Co}$, in the form of nanoparticles, is a potential alternative to noble-metal-based catalysts for the unsymmetrical Hantzsch condensation. The mildness of the conversion, experimental simplicity, compatibility with various functional groups, excellent yields, shorter reaction time, and easy work-up make this procedure attractive for the synthesis of a variety of these derivatives. Becasue this heterogeneous catalyst can be simply removed using an external magnetic device, it also enhances product purity and is economic.

\section{Acknowledgments}

We gratefully acknowledge financial assistance from the University Grants Commission, University of Kashan.

\section{References}

1 Safari J, Khalili S D, Rezaei M, Banitaba S H, Meshkani F. Monatsh Chem, 2010, 141: 1339

2 Peng Q, Yang Y, Yuan Y. J Mol Catal A, 2004, 219: 175

3 Fu H, Li M, Chen H, Li X. J Mol Catal A, 2006, 259: 156

4 Paulik F E. Catal Rev, 1972, 6: 49

5 Beller M, Cornils B, Frohning C D, Kohlpaintner C W. J Mol Catal A, 1995, 104: 17

6 Ungvary F. Coord Chem Rev, 2007, 251: 2087

7 Wen F, B.nnemann H, Jiang J, Lu D, Wang Y, Jin Z. Appl Organomet Chem, 2005, 19: 81
8 Bruss A J, Gelesky M A, Machado G, Dupont J. J Mol Catal A, 2006, 252: 212

9 Ma L, Peng Q, He D. Catal Lett, 2009, 130: 137

10 Anastas P T, Warner J C. In: Green Chemistry: Theory and Practice. Oxford: Oxford University Press, 1998

11 Kalinski C, Lemoine H, Schmidt J, Burdack C, Kolb J, Umkehrer M, Ross G. Synlett, 2008: 4007

12 Debache A, Ghalem W, Boulcina R, Belfaitah A, Rhouati S, Carboni B. Tetrahedron Lett, 2009, 50: 5248

13 Klusa V. Drugs Future, 1995, 20: 135

14 Bretzel R G, Bollen C C, Maeser E, Federlin K F. Am J Kidney Dis, 1993, 21(6s3): 53

15 Bretzel R G, Bollen C C, Maeser E, Federlin K F. Drugs Future, 1992, 17: 465

16 Rainer B, Volker G. Drugs Future, 1995, 20: 499

17 Janis R A, Triggle D J. J Med Chem, 1983, 26: 775

18 Boecker R H, Guengerich F P. J Med Chem, 1986, 29: 1596

19 Gaudio A C, Korolkovas A, Tkahata Y. J Pharm Sci, 1994, 83: 1110

20 Gordeev M F, Patel D V, Gordon E M. J Org Chem, 1996, 61: 924

21 Svetlik J, Veizerova L, Kittmann V. Tetrahedron Lett, 2008, 49: 3520

22 Suzuki I, Suzumura Y, Takeda K. Tetrahedron Lett, 2006, 47: 7861

23 Shaabani A, Bazgir A, Teimouri F. Tetrahedron Lett, 2003, 44: 857

24 Li M, Zuo Z, Wen L, Wang S. J Comb Chem, 2008, 10: 436

25 Sabitha G, Reddy G S K, Reddy C S, Yadav J S. Tetrahedron Lett, 2003, 44: 4129

26 Heravi M M, Bakhtiri K, Javadi N M, Bamoharram F F, Saeedi M, Oskooi H A. J Mol Catal A, 2007, 264: 50

27 Cherkupally S R, Mekalan R. Chem Pharm Bull, 2008, 56: 1002

28 Wang L M, Sheng J, Zhang L, Han J W, Fan Z Y, Tian H, Qian C T. Tetrahedron, 2005, 61: 1539

29 Ji S, Jiang Z Q, Lu J, Loh T P. Synlett, 2004: 831

30 Sainani J B, Shah A C, Arya V P. Indian J Chem Sect B, 1994, 33B: 526

31 Kumar A, Maurya R A. Tetrahedron Lett, 2007, 48: 3887

32 Ko S, Yao C F. Tetrahedron, 2006, 62: 7293

33 Tu S J, Yan S, Cao X D, Wu S S, Zhang X H, Hao W J, Han Z G, Shi F J. Organomet Chem, 2009, 649: 91

34 Zang H, Zhang Y, Zang Y, Cheng B-W. Ultrason Sonochem, 2010, 17: 495

35 Tu S J, Zhou J F, Deng X, Cai P J, Wang H, Feng J C. Chin J Org Chem, 2001, 21: 313

36 Wang X S, Shi D Q, Tu S J. Synth Commun, 2002, 32: 3449

37 Chen W Y, Lu J, Jin J R. Lett Org Chem, 2006, 3: 317

38 Kim S W, Son S U, Lee S S, Hyeon T, Chung Y K. Chem Commun, 2001: 2212

39 Safari J, Banitaba S H, Khalili S D. J Mol Catal A, 2011, 335: 46

40 Guo F, Zheng H, Yang Z, Qian Y. Mater Lett, 2002, 56: 906 